\title{
LA RURALIDAD QUILOMBOLA CUESTIONADA O LOS NUEVOS DESAFÍOS DE LA AGRICULTURA FAMILIAR EN BRASIL
}

\author{
Céline Raimbert \\ celine.raimbert@gmail.com \\ Université de Sorbonne Nouvelle - Paris 3, IHEAL / CREDA
}

\section{RESUMEN}

Entre urbanización y globalización, los espacios rurales están conociendo unas transformaciones esenciales. Es particularmente el caso de Brasil, gran potencia agrícola donde varios modelos agrarios se yuxtaponen, como, el agronegocio y la agricultura familiar. En este trabajo vamos a centrarnos en las evoluciones de las pequeñas comunidades rurales, sus dificultades y oportunidades, y más detalladamente en el ejemplo de las comunidades de remanentes quilombolas (descendientes de esclavos cimarrones), categoría socio-territorial establecida por el Estado en la Constitución Federal de 1988 en la que principios multiculturalistas se afirman. Reflexionaremos sobre las supuestas especificidades de la ruralidad quilombola, entre prácticas y representaciones, entre estrategias y valores, entre modernidad y tradición.

Palabras clave: ruralidad, agricultura familiar, comunidades quilombolas, Brasil.

\section{ABSTRACT}

Between urbanization and globalization, rural spaces are experiencing fundamental changes. It is particularly the case in Brazil, major agriculture power, where many agrarian models are overlapping, among these the agribusiness and the family agriculture. We will focus on the evolutions of the small rural communities, its difficulties and opportunities and, more precisely, on the example of communities of remnant Quilombolas (descendants of maroon slaves), socio-territorial category created by the State in the 1988 Federal 
Constitution in which the multiculturalist principles are affirmed. Thus, we will think about the specificities of the Quilombola rurality, between practices and representations, between strategies and values, between modernity and traditions.

Key words: rurality, family agriculture, quilombola communities, Brazil.

\section{INTRODUCCIÓN}

Aunque la agricultura solo representa el 5.8\% del (PIB) de Brasil, ${ }^{1}$ este país-continente sigue siendo una gran potencia agrícola, la tercera mundial después de los Estados Unidos de Norteamérica y de la Unión Europea. ${ }^{2}$ Algunos cultivos comerciales, como los de la soya o de la caña de azúcar (especialmente utilizada para el etanol), conocen un gran auge gracias al impulso de la agricultura de exportación (o agronegocio), que tiene su origen en la intensa modernización de la agricultura iniciada en los años setenta. Combinado con una urbanización galopante, ${ }^{3}$ tal fenómeno evidencia un mundo rural brasileño en plena transformación; es decir, «un dominio creciente y una subordinación del espacio y de la sociedad rural a los imperativos impuestos por la sociedad global a la que pertenece [...], [una] pérdida de autonomía de la sociedad rural cada vez más sumisa a una lógica social y económica exógena, o sea, la de la sociedad global que le impone el sentido de su evolución» (Jean, 1997: 29). En este contexto, Jean hace una pregunta: “¿Cómo definir la ruralidad? ¿Cómo pensar una ruralidad «moderna»?” (1997: 29). En efecto, más allá de las amenazas que hacen pesar tales evoluciones sobre el mundo rural, ${ }^{4}$ es importante interrogarse sobre las alternativas posibles del desarrollo rural en Brasil y sus consecuencias sobre los espacios y grupos rurales. ¿Entre el campesino tradicional y el agricultor moderno, será que no existe una tercera vía? ¿Y cuál podría ser? En efecto, numerosos son «los teóricos del campesinado [quienes] elaboraron tipologías binarias en las que el campesino tradicional y considerado como arcaico se opone al empresario agrícola moderno y considerado como vector de progreso social» (Deléage, 2005: 18). Aquí nos proponemos cuestionar la posibilidad de una alternativa entre estos dos arquetipos. 
Cuadro 1: La tipología binaria del campesino y del agricultor.

\begin{tabular}{|c|c|c|}
\hline \multirow{4}{*}{ Valores } & Campesino & Agricultor \\
\cline { 2 - 3 } & Estabilidad & Cambio \\
\cline { 2 - 3 } & Arraigo & Desarraigo \\
\cline { 2 - 3 } & Polivalencia & Especialización \\
\cline { 2 - 3 } & Papel de la tradición & Papel de la tecnología y del \\
& & mercado \\
\cline { 2 - 3 } & Economía de autosubsistencia & Economía mercantil e industrial \\
\hline Racionalidad & Social y moral & Técnica y económica \\
\hline
\end{tabular}

Fuente: Deléage (2005:18).

A partir de los años ochenta, tiempo de la transición democrática brasileña, aparecen movimientos sociales que critican el modelo agrícola modernizador y productivista, como el Movimiento de los Trabajadores Rurales Sin Tierras (M.S.T.) ${ }^{5}$, que defiende otro tipo de agricultura y vida rural. Esta tendencia acaba reflejándose en la Constitución Federal de 1988, a partir de la cual nuevas perspectivas salen a la luz, al tomarse en consideración les especificidades y multiplicidades de la sociedad brasileña. En un ámbito marcado por las influencias del multiculturalismo y del socioambientalismo ${ }^{6}$ (Santilli, 2005), se crean diferentes estatutos «fundiarios» que garantizan a grupos de pequeños productores rurales derechos territoriales y sociales, en forma de usufructo colectivo para las Tierras Indígenas (TI) (Estatuto do Indio, Ley $\mathrm{n}^{\circ}$ 6.001, 19/12/1973, seguido por el Artículo 231 da Constitución Federal) y las Reservas Extractivistas (Resex) (Ley nº 7.804, 18/07/1989, seguida por el Decreto n 98.897, 30/01/1990, dentro de la Política Nacional del Medio Ambiente), en forma de propiedad colectiva para los comunidades quilombolas.

Es entonces cuando se otorga a los quilombolas, descendientes de esclavos fugitivos (cimarrones), un estatuto fundiario oficial acompañado de derechos específicos; como el Artículo 68 de las Disposiciones Transitorias de la Constitución Federal lo estipula: «Se reconoce a los remanentes de las comunidades de quilombos que ocupan las tierras [de sus antepasados] la propiedad definitiva, el Estado debiendo emitir los títulos respectivos». Después de una primera titularización en 1996, Brasil cuenta hoy en día con 110 
comunidades quilombolas tituladas, lo que representa un total de 11,559 familias y 963,015 ha distribuidas entre 15 de los 26 estados de la Federación. Además, existen 1,081 casos en el proceso de regularización en 24 estados, lo que evidencia una tendencia al crecimiento del peso de las comunidades quilombolas, cuya importancia fue reafirmada en 2003 a través del Decreto Presidencial ${ }^{7} n^{\circ} 4.887$, mismo que normaliza el proceso administrativo de regularización de los territorios quilombolas. Desde un punto de vista organizacional, la comunidad quilombola se organiza en asociación, la cual es la única propietaria legal del título fundiario. Así, la asociación es la representante oficial de la comunidad quilombola, su interlocutor con las instituciones gubernamentales o no gubernamentales.

$\mathrm{Al}$ analizar esa tendencia y focalizar el caso de las comunidades quilombolas, proponemos aquí interrogar las evoluciones recientes de la ruralidad y sus representaciones. A partir del caso quilombola, ¿en qué medida podemos considerar que esos nuevos procesos socioterritoriales pueden permitir modelar nuevas perspectivas de la ruralidad en Brasil? ¿Según qué modalidades y qué alternativas del desarrollo rural? Para contestar esas preguntas, vamos a concentrar nuestra atención sobre el caso de la comunidad quilombola de Abacatal, titulada el 13 de mayo de 1999. Compuesta de 76 familias (330 individuos), ${ }^{8}$ la comunidad rural forma parte del municipio de Ananindeua, en la Región Metropolitana de Belém do Pará. Situada a unos 20 kilómetros de la capital del estado amazónico y a 8 kilómetros del centro de Ananindeua, Abacatal se encuentra en posición periurbana y sufre presiones urbanas crecientes (la invasión urbana de Aurá sigue extendiéndose a lo largo de la pista que llega a la comunidad quilombola). Nuestro enfoque privilegiará el análisis de los discursos de los habitantes de Abacatal, por una parte, y de las instituciones oficiales, por la otra, e intentará también confrontarlos con las realidades objetivas. Este estudio es el fruto de una investigación de campo realizada entre septiembre y diciembre de 2009, que se basó, más allá de la observación participante, en entrevistas semi-directivas acompañadas con cuestionarios socioeconómicos ante una muestra de 24 unidades domésticas escogidas de forma aleatoria. 
Empezaremos con una reflexión sobre las especificidades de las representaciones de la ruralidad entre los quilombolas. Tras analizar los discursos de los habitantes de Abacatal, se evidenciará una ruralidad profundamente relacionada con la identidad quilombola, la cual se vive y se reivindica. Pero la ruralidad es también un conjunto de prácticas agrícolas o no. En su transformación, parece orientarse hacia nuevos mercados oportunos. Finalmente, trataremos de entender cómo la defensa y la declaración de la ruralidad entre los quilombolas se vuelve una estrategia, una forma de diferenciación para integrarse a una nación brasileña, construida según los principios del multiculturalismo y del socioambientalismo.

\section{DEL CAMPESINO AL QUILOMBOLA: EL SURGIMIENTO DE UNA RURALIDAD ETNOPOLÍTICA}

El modelo del quilombola surge recientemente, gracias a la promulgación del Artículo 68 de las Disposiciones Transitorias de la Constitución Federal de 1988. Entonces, quienes hasta ahora eran denominados mayoritariamente campesinos negros, caïpiras, ${ }^{9}$ caboclos $^{10}$ u otros ribereños, ${ }^{11}$ son re-calificados y re-semantizados bajo la figura de quilombolas. ¿Qué significa esto? ¿Cómo evoluciona su relación con la ruralidad a partir de dicho cambio? Podemos anotar que esta cuestión está muy vinculada con el tema de la relación que tiene cada población con la tierra y el territorio, relación que pone en evidencia las prácticas de una ruralidad específica. Así, según Kayser (1990), la relación con la localidad sería el primer elemento de identificación de los rurales y, por consiguiente, uno de los núcleos de la definición de la ruralidad. Parecería entonces que las modalidades de la relación estrecha con el territorio, el conocimiento y el reconocimiento de los lugares pudiera fundar la identidad conceptual del rural. El espacio rural se define por un modo particular de uso y apropiación, tanto práctico como simbólico, del territorio. Apoyándonos más específicamente sobre un análisis de las representaciones territoriales de los habitantes de la comunidad quilombola de Abacatal, trataremos de destacar las características de su ruralidad. 
DESDE LAS DECLINACIONES DEL TERRITORIO QUILOMBOLA...

Es importante recordar, en primer lugar, que los quilombolas constituyen una población mayoritariamente compuesta por trabajadores rurales. Sus comunidades corresponden históricamente a grupos sociales situados en espacios rurales más o menos marginados, concebidos como «tierras de negro», tierras conquistadas, heredadas u ofrecidas; caracterizadas, entre otras cosas, por el uso común (Almeida, 1989). ${ }^{12}$ Las actividades principales de los quilombolas se basan en prácticas agro-extractivas diferentes en función de los recursos naturales presentes en sus territorios. En Abacatal, por ejemplo, domina el cultivo de la yuca, la fruticultura (sobre todo el cupuaçu (Theobroma Grandiflorum), el açaí (Euterpe oleracea) y el acerola (Malpighia punicifolia)), y la extracción del carbón vegetal. En 24 grupos domésticos consultados, cerca del 70\% de la muestra declaró a la yuca o el carbón como principal fuente de ingresos, ${ }^{13}$ por lo que la tierra constituye, ante todo, un lugar de trabajo y de explotación de los recursos naturales necesarios para la subsistencia. El espacio rural quilombola aparece como un territorio-recurso, una clase de «infraestructura socio-económica» (Di Méo y Buléon, 2005: 72) formada por los lugares útiles para la reproducción del grupo, ya sea que se trate de campos de cultivo (roça, en portugués), zonas de plantación de árboles frutales, depósitos de extracción de madera o de piedras y otros territorios de caza y pesca. No obstante los usos antes mencionados, no podemos limitar ese territorio-recurso a una función utilitaria y estructural, como si las prácticas del territorio no pudieran expresar otra cosa que una pura y simple explotación de los espacios. Di Méo y Buléon explican cómo «la economía influye, al más alto grado, las prácticas y las apropiaciones identitarias y afectivas del espacio» (Di Méo y Buléon, 2005: 90).

Definida como un depósito de recursos, la tierra representa también para las poblaciones quilombolas un capital social y simbólico, pues el espacio de trabajo se confunde con el de vida; es decir, el lugar donde se vive (según cierto modo de vida y ciertas referencias afectivas) y el espacio desde donde se vive y se ve el mundo. Así, el espacio rural supera su propia dimensión física. Incorpora representaciones sociales y culturales y se vuelve 
territorio. El territorio se construye por «la relación privilegiada de designación, de apropiación, de calificación» (Di Méo y Buléon, 2005: 31) de un espacio e implica, no solo la racionalidad del ser humano (como productor y organizador del espacio), sino también su dimensión afectiva. De esta manera, un territorio-identidad se superpone sobre el territoriorecurso y se vuelve un "geosímbolo», según el concepto elaborado por Bonnemaison para denominar «un lugar, un itinerario, un espacio que toma, para pueblos y grupos étnicos, una dimensión simbólica y cultural, donde sus valores se arraigan y su identidad se confirma» (1981: 249).

Es el caso en Abacatal, donde el vínculo con la tierra tiene esas dimensiones múltiples. Para interrogar esos espacios vividos y reflexivos, vamos a interesarnos en los individuos y sus representaciones y percepciones propias, ${ }^{14}$ Entonces, veremos cómo la historia de los abacataenses como grupo de parentesco y de solidaridad se relaciona con su territorio. En efecto, todo el mito fundador de la comunidad que les permitió acceder al estatuto quilombola se basa en una leyenda que mezcla esclavitud, parentesco y tierra. La historia, ${ }^{15}$ que nació en el siglo XVIII (se mencionan los años 1710 o 1790), dice que la comunidad quilombola de Abacatal se componía originariamente de los miembros de una misma familia, con más precisión, de tres hermanas mulatas (las «Tres Marías»), resultados de la unión de una esclava africana llamada Olímpia con el conde Coma Mello, dueño portugués del ingenio local (engenho, en portugués). Sin descendencia legítima, antes de morir, legó a sus hijas su hacienda (fazenda, en portugués), la cual hoy en día corresponde parcialmente al territorio abacataense. ${ }^{16}$ Esta historia oral se repite entre los abacataenses con cualquier visitante que llega a la comunidad, a fin de seguir legitimando la concesión de la propiedad de las tierras.

Así es como el territorio trae consigo una historia, y por ello una ancestralidad fuerte y reivindicada. Tierra de los antepasados, la tierra quilombola se percibe como una herencia que hay que conservar, un origen común a todos los miembros de la comunidad que justifica a la vez su presencia y unidad social. Pues en Abacatal, en la lengua corriente, ser 
quilombola o ser «heredero» (herdeiro, en portugués) no tiene una clara distinción y expresa, en todos los casos, una reivindicación territorial. De hecho, ser quilombola significa también estar luchando, y más particularmente luchando para un territorio. Muy a menudo, la historia de las comunidades quilombolas se relaciona con conflictos de tierras que, en el mejor de los casos, desembocan en la titularización de las mismas. En efecto, muchas veces son situaciones de crisis fundiaria (amenaza de expulsión) las que inician la reivindicación quilombola. Abacatal no es una excepción y el proceso de reconocimiento quilombo empezó con una historia de «grilagem» ${ }^{17}$ y una amenaza de expulsión particularmente violenta. ${ }^{18}$ Así, la tierra es a la vez un medio de subsistencia para trabajadores rurales, un origen y un patrimonio para herederos, unos bienes reivindicados $y$, después, adquiridos a costa de muchos esfuerzos y muchos sufrimientos.

De esta forma podemos hablar de una verdadera identidad territorial de las poblaciones quilombolas. Esta identidad de origen, de trabajo y de lucha es unificadora y fundamental. La tierra lo representa todo para estos individuos, tal como ellos mismos lo expresan constantemente. El señor Benedito ${ }^{19}$ añade: «La tierra es nuestra vida. Todo lo que tenemos, son la tierra y el agua. Es de la tierra de donde todo procede. En la tierra, yo cultivo la macaxeira, la mandioca, ${ }^{20}$ las papas, crío las gallinas, los cerdos y el ganado. Ella es nuestra madre, la tierra madre». Vemos pues que según el relato la tierra es primero un elemento del cual se obtiene la subsistencia y la alimentación. Después Benedito la presenta como una entidad, una imagen materna. Entonces se vuelve una metáfora encarnada, el origen, la madre nutricia, una figura tutelar que dirige la existencia, por la cual y para la cual se vive. Esta intimidad que se desarrolla con la tierra (y por extensión con el territorio que incluye a esta tierra específica) da lugar a una identificación profundamente arraigada y fortalecida por el riesgo de perder dicho elemento. Es así como el territorio-recurso y el territorio-identidad se mezclan y se confunden. 
HACIA LAS DIVERSAS REPRESENTACIONES DE LA RURALIDAD: RURALIDAD PRÁCTICA, RURALIDAD POLÍTICA.

Después de haber analizado el vínculo entre ruralidad y usos — prácticos e ideales - de los territorios quilombolas, veremos cómo la ruralidad puede interpretarse a través de los mecanismos de la identidad quilombola que se revelen particularmente estratégicos. La dimensión afectiva e identitaria de la tierra se relaciona profundamente con el trabajo agrícola, interpretado como un patrimonio que hay que defender, a la vez que se piensa como una tradición ancestral y un poderoso motor identitario. Así, la mayoría de las veces, los habitantes contestaban a la pregunta sobre lo que para ellos representa la tierra mezclando historia, identidad y recursos económicos:

Nuestra estabilidad depende de la tierra, nuestra cultura se relaciona con la tierra, desde nuestros antepasados que construyeron aquella tierra para nosotros. Hay una relación muy fuerte, una historia. Es ella la que nos da nuestra subsistencia. Sacamos de ella nuestra subsistencia para nuestra familia. Para nuestra supervivencia (...) Nuestra cultura es desarrollar el trabajo de la tierra. Porque nuestros antepasados siempre trabajaron, siempre cultivaron, siempre plantaron y hoy sigue siendo así. Todo el mundo tiene un pedacito de campo, un pedacito de plantación, pero seguimos cultivando, no abandonamos aquella cultura. Es la única cultura que sigo viendo aquí, en Abacatal, es plantar y cultivar la tierra. ${ }^{21}$

Es así como el territorio-recurso se convierte en un símbolo para la comunidad y el trabajo de la tierra, la agricultura, se erige en identidad. Para los abacataenses, el valor de la tierra y de los hombres se mide según la manera cómo esta se labra y se trabaja. Se critica a tal grupo doméstico que no explota su parcela, se reconoce a otros que «invadieron» (ocuparon sin permiso) otra parcela e incluso se señala que, a pesar de todo, le sacan buen partido porque cumplieron las tareas agrícolas. Entonces, aunque todos los habitantes de Abacatal no sean trabajadores agrícolas propiamente dicho, todos efectúan estas actividades, bien sea porque están acostumbrados a ayudar a la familia o para obtener ingresos complementarios, en especial gracias a la producción de carbón, el cual tiene la característica de ser rentable de inmediato. La importancia del papel del trabajo agrícola en el seno de Abacatal se ilustra 
también, de forma anecdótica, con el cambio de nombre de la Asociación -de Asociación de los Habitantes de Abacatal, pasó a ser Asociación de los Productores y Habitantes Quilombolas de Abacatal. Además de la adición del calificativo quilombola notamos la de la palabra «productores», que se ubica en primer lugar.

Si tenemos en cuenta que la Asociación constituye no solo la personalidad jurídica de la comunidad, sino también su vitrina en el exterior, ese cambio es muy significativo. Así, si se considera el conjunto de los abacataenses como productores, cada habitante se vincula con la tierra gracias a una clase de cordón umbilical, lo que implica que sin ella no pueden sobrevivir. Sin minimizar las características identitarias y simbólicas, esta decisión tiene implicaciones políticas que analizaremos luego. Entonces, la identidad quilombola se muestra profundamente rural y se construye sobre el trabajo de la tierra. Pero no cualquier tierra: es la de los antepasados y de los orígenes. Pues la ruralidad de las poblaciones quilombolas se carga de un obvio valor cultural y simbólico, para no decir étnico.

El carácter quilombola se presenta como un valor añadido a los rasgos del sencillo campesino negro que fue, durante mucho tiempo, el objeto de un estigma más que de una valorización. En la actualidad, la identidad quilombola representa un orgullo para todos los que la comparten. El quilombola es el «Negro», descendiente de esclavos, sublimado en la lucha y la resistencia. La herencia no es solo material, sino también cultural y simbólica; se refiere a un origen común que finalmente se autorizan a reivindicar y valorizar. Observamos entonces una clase de actualización de una identidad quilombola que ya no se contenta con inscribirse en la historia y el pasado lejano. La identidad histórica se convierte en una identidad de lucha y de reivindicación, y en esta medida se convierte en una identidad renovada del oprimido que lucha para cambiar su posición: «Para mí, ser quilombola significa ser un pueblo que lucha, un pueblo que nunca renuncia a su origen, que no renuncia a su pasado, un triste pasado de lucha, de sangre derramada, de sudor. Pero es un pueblo que tiene una historia. El quilombo han sido personas que se han refugiado para ir en busca de cosas mejores, de libertad. Así, para mí, ser quilombola es ser libre. Es 
siempre luchar por aquella libertad. Ser libre». Presentamos aquí las palabras de María Santana da Costa Barbosa, 40 años. Descendiente de una de las familias clave de la comunidad (una de las tres hermanas mulatas), basó su legitimidad liderando, con algunos otros compañeros, la comunidad durante el conflicto fundiario. Podemos decir que su discurso refleja lo que fue y sigue siendo una clase de discurso oficial de la comunidad quilombola de Abacatal.

Entonces, la ruralidad de estas poblaciones se hace política y desempeña un papel fundamental no solo para la supervivencia material del grupo, sino también para su reproducción social y simbólica; forma parte de sus argumentos de reivindicación. Así parece justificarse su lazo consubstancial con la tierra y, por consiguiente, la concesión del título de propiedad colectiva. Los textos de leyes oficiales muestran esa doble función del territorio quilombola, tierra nutricia dual, compuesta tanto de recursos naturales necesarios para la subsistencia como de símbolos constitutivos del grupo: «Artículo 4 : Se consideran como tierras ocupadas por remanentes de las comunidades quilombolas todas las tierras utilizadas para la garantía de su reproducción física, social, económica y cultural, tanto como las áreas provistas de recursos naturales necesarios para la preservación de sus costumbres, tradiciones, culturas y distracciones, incluyendo los espacios de vivienda, los espacios usados para los cultos religiosos y los emplazamientos que contenían las reminiscencias históricas de los antiguos quilombos» (Instrucción Normativa INCRA n ${ }^{\circ}$, del 24 de marzo de 2004). ${ }^{22}$

La ruralidad de los quilombolas no se relaciona solo con unas formas de producción económica, de explotación del territorio, sino también con unas formas sociales y culturales. Podemos recordar aquí que la identidad quilombola sigue siendo un instrumento legal que permite a poblaciones rurales acceder a la propiedad de la tierra, tanto como a varios derechos específicos que les permiten adquirir un estatuto legal particular; la ruralidad se vuelve una reivindicación en sí misma y, por ende, se erige en ideología. De esta manera, la cuestión ideológica constituye una introducción en el terreno político de los 
mecanismos identitarios y forma un sistema que procura « describir, explicar, interpretar o justificar la situación de un grupo o de una colectividad» (Roche in Di Méo y Buléon, 2005:112). El principio ideológico ofrece una orientación propia a la acción histórica de este grupo o de esta colectividad. En este sentido, Larrea Killinger y Ruíz-Peinado Alonso (2004: 193) hablan de un «pulso entre una identidad cultural viva y dinámica que da sentido a la idea de pertenencia de una comunidad o pueblo, y una identificación política cuyo lenguaje se esfuerza por clasificar, homogeneizar y fijar la dinámica de las identidades culturales a través de políticas, leyes y conceptos específicos». Respecto a nuestro caso, los mecanismos se organizan alrededor de la cuestión quilombola y su consubstancialidad con el territorio. Estratégica, la reivindicación de la ruralidad acaba apoyando la defensa de un modelo y de un modo de vida propio que distingue al quilombola del campesino negro.

La identidad quilombola da un valor mayor a estas poblaciones rurales, una identidad teñida de etnicidad. En efecto, los textos oficiales atribuyen a los quilombolas características socioculturales propias, como lo demuestra el Decreto Presidencial n 4887, del 20 de noviembre de 2003: «Se consideran como remanentes de las comunidades quilombolas, para los fines de este Decreto, los grupos étnico-raciales, según criterios de auto-atribución, con una trayectoria histórica propia, dotados de relaciones territoriales específicas, con la presunción de una ancestralidad negra vinculada a la resistencia y a la opresión histórica sufrida». Por otra parte, este punto de vista oficial, que responde al principio multiculturalista integrado a la política brasileña, se ve recuperado localmente para apoyar las reivindicaciones territoriales de comunidades rurales amenazadas. Así, la ruralidad puede entenderse como el fruto de un diálogo entre políticas y discursos oficiales, por una parte, y poblaciones marginadas en busca de legitimidad y ciudadanía, por otra parte. Como Véran (2003: 8) enfatiza, la figura del quilombola surge en el momento de la conjunción entre una oferta política (el reconocimiento del estatuto quilombola) y una reivindicación social. ${ }^{23}$ 
Larrea Killinger y Ruiz-Peinado Alonso dicen que «el marco legal y administrativo no está lo suficientemente consolidado para constituir el único espacio de reivindicación de las demandas quilombolas, así que la identidad pasa por autodefinirse en un momento histórico de visibilización social y de reinterpretación a partir de la relación con otros movimientos sociales como el negro, el ecologista, el académico y el religioso (pastoral), el político y el sindical» (2004: 193). En este contexto, adaptándose a las definiciones oficiales del quilombola, el campesino negro en lucha se muestra eminentemente político, organiza de forma estratégica un conjunto de instrumentos útiles para su conversión a la identidad quilombola, dentro de los cuales la ruralidad constituye un elemento mayor. Esta estrategia, además de reflejarse en las representaciones y discursos de los quilombolas, también aparece en sus prácticas, demostrando una doble adaptación a las exigencias de la sociedad y economía modernas, tanto como a las categorizaciones organizadas por el Estado que hacen hincapié en las tradiciones ancestrales y los saberes territoriales de tales poblaciones, para no hablar de su supuesta armonía con la naturaleza (Santilli 2005: 135). ${ }^{24}$

\section{HACIA UNA RURALIDAD ALTERNATIVA: PRÁCTICAS RENOVADAS Y AMBIVALENTES}

La ruralidad no se expresa solo a través de las representaciones, percepciones y discursos de su pueblo, sino también, de forma más concreta, mediante sus prácticas y actividades agrícolas o no. Así, veremos aquí cómo esas prácticas se reformaron para encontrar alternativas y estrategias de viabilidad del trabajo y de la producción en un medio rural de pequeños productores amenazados por los fenómenos de atracción urbana, combinados con el peso cada vez mayor de la agricultura productivista e intensiva. Al combinar la lógica de subsistencia con la del mercado, el objetivo de esos pequeños trabajadores rurales, y especialmente los quilombolas, es crear y tomar parte en nuevas formas de organización del sistema de producción y de la vida local, tal como Gelhen lo afirma: «para viabilizar cada alternativa, el agricultor familiar tiene que formarse sobre las cuestiones de tecnología, de gestión y de mercado y recrear redes de solidaridad, no solo basadas en lazos de compadrazgo, parentesco o religioso, sino sobre la vecindad, la afinidad profesional; es 
decir, sobre criterios racionales» (en Zanoni et al., 2001: 63). En este contexto, ¿cómo se re-organizan los quilombolas? ¿Según cuáles criterios y cuáles realidades?

Intentaremos evidenciar toda la ambivalencia de esta ruralidad alternativa que se sirve de los incentivos e imágenes de la tradición para integrarse en los procesos y mecanismos de la modernidad. A partir del caso de Abacatal y algunos ejemplos de comunidades quilombolas visitadas (entre 2009 y 2011) en el Vale do Ribeira, estado de São Paulo, ${ }^{25}$ observaremos un doble movimiento compuesto en principio por prácticas agrícolas de preservación del medio ambiente, y después un crecimiento de la pluriactividad que dirige las prácticas de los rurales hacia actividades no agrícolas, a veces urbanas, en los sectores de servicios, comercio o la industria.

\section{EL ESPACIO RURAL, UN PATRIMONIO ECOLÓGICO Y CULTURAL}

$\mathrm{Al}$ seguir los debates y políticas sobre el desarrollo sostenible, los proyectos que toman en consideración las problemáticas ambientales están aumentando constantemente, apoyados por varios órganos gubernamentales y no gubernamentales acostumbrados a trabajar con las comunidades quilombolas. Esto se da especialmente en el caso de los Sistemas AgroForestales (SAF), cuyo objetivo es reunir diferentes tipos de cultivos y/o plantaciones sobre diferentes estratos con el fin de recuperar áreas degradadas y re-introducir una práctica agrícola familiar. En Abacatal, por ejemplo, un (SAF) fue desarrollado en 2004 con el apoyo de la EMATER (Empresa de Asistencia Técnica y Extensión Rural). Organizado alrededor de una media docena de familias, dicho sistema combina plantaciones de cupuaçu (Theobroma grandiflorum), castaño de Brasil (Bertholletia excelsa) y granadilla (Passiflora ligularis) con el uso de abono orgánico. Se encuentran también SAFs en las comunidades quilombolas del Vale do Ribeira, creados gracias a las formaciones proporcionadas por el Instituto Socioambiental (ISA). ${ }^{26}$ De la misma forma se apoyan proyectos de apicultura y piscicultura o de artesanado (de bisutería y objetos de cerámica en Abacatal, de objetos de fibras de plátano y madera en el Vale do Ribeira). Un último ejemplo sería el desarrollo desde hace varios años de la producción de plátanos orgánicos y 
su transformación en dulce de plátano para vender en la comunidad quilombola de Ivaporunduva, con el apoyo del (ISA). ${ }^{27}$

Todas esas incitaciones demuestran una voluntad de desarrollar entre las comunidades quilombolas una agricultura supuestamente más ecológica y menos depredadora para los ecosistemas forestales. Así es como, legalmente, las comunidades quilombolas son consideradas «áreas protegidas», tanto como las Tierras Indígenas, debido a un supuesto uso de los recursos naturales de impacto débil. Además, vemos aquí nuevamente cómo tales políticas representan a los quilombolas a modo de «poblaciones tradicionales». Al respecto, el texto de Zanoni et al. (2001:329-330) trata de definir sus principales características mostrando cómo el concepto mismo de quilombola sugiere tanto una dependencia -incluso una simbiosis de esta población rural con la naturaleza y un modo de vida específico- como también un profundo conocimiento de la naturaleza. Asimismo, este texto hace hincapié en el papel clave desempeñado por el territorio en el que el grupo social se reproduce económica y socialmente, en la importancia dada al parentesco y compadrazgo para el ejercicio de las actividades económicas, sociales y culturales, o en la reivindicación de una cultura diferente. Es así como surge una categoría de trabajador rural más interesado por las cuestiones de medio ambiente y el espacio de vida, al que Brandenburg se refiere como: «otro personaje en la agricultura: el agricultor familiar alternativo-sostenible» (en Zanoni et al., 2001:175), que implica una nueva forma de vida rural orientada hacia una agricultura menos depredadora. En este contexto, los quilombolas actúan de forma estratégica y se adaptan a esas nuevas representaciones practicando ese nuevo tipo de actividades, mismas que podríamos considerar como clases de nichos socioeconómicos que garantizan a los quilombolas un lugar especial en el Brasil globalizado de hoy en día.

En relación con lo anterior, lo rural —ahora concebido como espacio de vidaexperimenta una diversificación cada vez mayor en sus actividades. Todo aquello relacionado con el turismo rural, ecológico o étnico, como alternativas sostenibles y 
viables, está desarrollándose cada vez más y ayudando a convertir el espacio rural en un patrimonio ecológico y cultural común. El «terroir» ${ }^{28}$ como capital explotable, se convierte progresivamente en un bien de consumo cultural, modelando los contornos de una ruralidad multiforme que se adapta a los requisitos de su época, al mismo tiempo que se basa en valores supuestamente tradicionales y ancestrales. Ferreira evidencia «el surgimiento del uso del espacio rural como lugar de recreación y como medio ambiente, como paisaje que tiene un valor en sí mismo, una especie de facilidad rural que puede ser la fuente de un renacimiento rural, especialmente cerca de las áreas metropolitanas» (en Zanoni et al., 2001:180). El territorio quilombola, en tanto nuevo objeto de valorización económica, se vuelve atractivo, particularmente para los turistas urbanos en busca de naturaleza salvaje y tradiciones inmemoriales.

Tal turismo está desarrollándose entre las comunidades quilombolas del Vale do Ribeira, con apoyo del ISA. Así, en el marco del desarrollo de un turismo étnico-cultural, la comunidad quilombola de Ivaporunduva empezó a acoger a grupos de estudiantes y otros visitantes. Dentro de las actividades programadas se imparten conferencias sobre la historia y las características de la comunidad, y se propone a los turistas ir por los caminos del territorio quilombola, visitar los campos y comer algunas de las especialidades culinarias. Además, una posada, construida con el apoyo del Estado de São Paulo y especialmente del ITESP (Instituto de Tierras del Estado de São Paulo) y la PETROBRAS (Petróleo Brasileiro S.A.), recibe a los turistas. Para recibir esas visitas, ciertos habitantes asistieron a una formación de guía ambiental. Es el caso de Ladio Santos, 27 años, quien es natural de Ivaporunduva, donde toda su familia vive. Hasta sus 20 años trabajaba en la construcción como pintor de brocha gorda. Las empresas tienen la costumbre de buscar en el campo una mano de obra más barata para ir a trabajar en las obras de las ciudades de la región. Así fue como Ladio, empleado por esas empresas, pasaba gran parte del año fuera de la comunidad, en viviendas reservadas para esos trabajadores del campo. Hace unos diez años, el proyecto de turismo quilombola apareció y Ladio aprovechó la ocasión de cambiar de trabajo y quedarse con su familia. Empezó la formación de seis meses de guía ambiental. Después de 
un periodo de prácticas de diez meses en una unidad de conservación, Ladio acabó trabajando en el Vale do Ribeira, proponiendo a los turistas visitas de grutas o de su comunidad a través de varias marchas y otras atracciones locales. Finalmente, estas actividades muy recientes resaltan el reposicionamiento del vínculo entre la tierra y el trabajo, y, por consiguiente, la recomposición de la ruralidad Con más y más posibilidades de actividades, la tierra ya no es la única fuente de trabajo.

\section{DIVERSIFICACIÓN DE LAS PRÁCTICAS RURALES: LA CUESTIÓN DE LA PLURIACTIVIDAD}

Como hemos mencionado antes, actualmente es posible observar en espacios rurales de agricultura familiar, como las comunidades quilombolas, un crecimiento de la población activa rural no-agrícola, en su mayoría dedicada a actividades comerciales, industriales o administrativas (Medeiros Paoliello, 2006). Esto nos permite interrogarnos sobre las nuevas significaciones del espacio rural que aparecen y se yuxtaponen. Ya no se trata solo de un depósito de recursos naturales para explotar, sino también un patrimonio, un lugar de recreación y de residencia. En Abacatal, por ejemplo, el número de trabajadores asalariados representa actualmente cerca del $19.5 \%$ de la población activa de la comunidad, frente a $14.5 \%$ en $1998 .{ }^{29}$ Así, la mayoría de los asalariados trabajan fuera de Abacatal, esencialmente en áreas urbanas. La proximidad a la ciudad, como verdadero mercado laboral, facilita la pluriactividad de los rurales, lo que se refuerza por una percepción altamente positiva del trabajo remunerado entre los habitantes de la comunidad. Frente a la pregunta sobre las mejores opciones de futuro para sus hijos, varios individuos (el 25\% de la muestra interrogada) contestaron «un buen trabajo» o «un trabajo remunerado». Aunque se trate solo de percepciones prospectivas y no de las reales evoluciones que Abacatal posiblemente conozca, podemos ver en esas respuestas, por lo menos, el esbozo de una tendencia. En el imaginario común, el trabajo remunerado parece, pues, representar una posibilidad de ascenso social, incluso mínimo, gracias a la garantía de un sueldo regular. En cambio, en lo que se refiere a la escuela, podemos observar un mayor consenso. A la pregunta previamente enunciada fue la respuesta más dada (el 62.5\% de la muestra); al 
evocar para los habitantes de Abacatal la promesa de un futuro mejor o por lo menos diferente; esto parece sugerir una aspiración a abandonar la agricultura familiar.

Ahora bien, decir que estas aspiraciones ponen en tela de juicio el apego a la ruralidad sería sin duda algo caricaturesco puesto que la pluriactividad, aunque cada vez más significativa, siempre ha formado parte de la historia de la agricultura familiar en Brasil (Gelhen en Zanoni et al., 2001:74). Esta puede también representar una estrategia de supervivencia y permanencia del grupo rural en su territorio, a la vez que sugiere también una exploración de nuevas oportunidades, como acabamos de ver con el caso de las actividades turísticas. En este contexto, aparece como un medio para captar recursos externos, para mejorar la calidad de vida y el sistema de producción agrícola de la comunidad. Así, la pluriactividad puede también contribuir a la persistencia de un estrecho vínculo con la agricultura. Como Ferreira (citado por Zanoni et al., 2001) muestra, la pluriactividad genera en ciertos casos ingresos iguales o superiores a los que se derivan de las actividades agrícolas, lo que permite la reproducción social de la familia tanto como la continuidad de un modo de vida altamente valorizado. En efecto, la pluriactividad y especialmente el trabajo remunerado pueden ser un medio para reducir la presión en el trabajo agrícola, así como en los recursos naturales en general y las tierras cultivadas en particular. La pluriactividad se muestra entonces más necesaria en un contexto marcado por la presión urbana sobre las tierras rurales, el empobrecimiento de los suelos, el crecimiento demográfico en las comunidades locales y las restricciones de uso debido a las leyes ambientales.

En esta difícil situación, la comunidad rural quilombola necesita intercambios y vínculos para subsistir. De ahí que la relación con la ciudad pueda reactualizarse y redefinirse constantemente, en un juego de interacciones e interdependencias, donde la proximidad entre los espacios urbanos y rurales ha ido en progresión. Frente a esto, la ruralidad se vuelve flexible, integra lo urbano, en suma, se adapta a los mecanismos y dinámicas de la modernidad. Esa permeabilidad de la ruralidad de los quilombolas da lugar a situaciones inéditas caracterizadas por esa ambivalencia. Una de estas situaciones es la co-residencia, ${ }^{30}$ 
que opera a través de una compleja movilidad entre lo rural y lo urbano. César, habitante de Abacatal y trabajador en la construcción, intentó la experiencia de ir y volver cada día de un espacio a otro, con la intención de adquirir una casa en Belém. Pero el tiempo perdido en los itinerarios y los peligros de la carretera (en mal estado y conocida por sus ataques) lo incitaron a abandonar esa opción. Ahora él reparte su tiempo entre Belém, donde vive con los padres, y Abacatal, adonde se reúne con su esposa y sus hijos cada fin de semana. César encarna el ejemplo-tipo de ese nuevo modo de vida rural en lo urbano, urbano en lo rural, que se expresa en parejas o individuos multilocalizados, cuya movilidad es cada vez más exacerbada. Gracias a sus recorridos, ellos refuerzan y facilitan la circulación de las personas, de los bienes y de los servicios, acercando a través de su acción los entornos urbanos y rurales. La co-residencia «difumina las distinciones rural-urbano y hace de la migración rural-urbana un proceso de extensión en vez de un sencillo evento» (Padoch et al., 2008:4).

La ruralidad parece incluir la movilidad, se aproxima a lo urbano, experimenta sus influencias y de esta forma evoluciona hacia una mayor ambivalencia. Thomsin (2001) critica el concepto de «urbanización del campo» ${ }^{31}$ para redefinirlo como un «proceso de integración de la movilidad espacial en el día a día; movilidad de personas y de bienes, pero, también movilidad de mensajes e ideas. (...) Desde ese punto de vista, la urbanización del campo, tal y como se la entiende, ya no es un proceso de asimilación sino de integración de categorías de poblaciones, incluso retrasadas, en la modernidad» (2001:6). Así, valores y prácticas urbanos se incorporan a la ruralidad quilombola, lo que a primera vista puede parecer contradictorio o llevar a cierta confusión. Quizá sea ya la hora de superar esa aparente contradicción y pensar en las implicaciones y significaciones de una ruralidad profundamente dual, que integra lo urbano sin asimilarse. 
RURALIDAD DIFERENCIADA, RURALIDAD SITUACIONAL: LA ESTRATEGIA QUILOMBOLA.

TRANSFORMACIONES RURALES: MECAMISMOS DE RECOMPOSICIÓN Y ADAPTACIÓN.

La presión y la proximidad urbanas no significan inevitablemente la desaparición de lo rural. En palabras de Di Méo y Buléon, «lo periurbano (...) no es [necesariamente] sinónimo de identidad y territorialidades desaparecidas o difuminadas» (2005: 95). Incluso, como lo hemos venido explicando, ruralidad y territorio rural se recomponen para adaptarse y se reafirman para integrarse. Una cultura rural persiste, mientras se adopta la cultura moderna más urbana. Al analizar los discursos de los habitantes de Abacatal veremos que la comunidad quilombola, incluida en la Región Metropolitana de Belém, parece corresponder a esta definición. Aunque integrada en un importante sistema urbano, la comunidad sigue conservando y preservando sus especificidades y su ruralidad. Concebida como parte de la identidad de Abacatal, los habitantes reivindican esta ruralidad. Ellos dicen ser del campo y se sienten orgullosos de esta situación. La ciudad, aunque admirada y deseada, representa ante todo una especie de gran depósito donde se almacenan los servicios y productos de consumo. Es por esto que su relación con la ciudad es básicamente funcional, dado que solo responde a necesidades precisas de los habitantes que, sin embargo, prefieren la tranquilidad del campo. En sus discursos, muchas veces ellos reproducen el mito de lo rural alrededor de la serenidad y del silencio del campo, reino del bienestar. Las posibles asimilación y homogeneización del espacio rural con el conjunto urbano pueden entonces ser cuestionadas. A este respecto, los comentarios de los habitantes de Abacatal son bastante elocuentes, como los siguientes ejemplos lo muestran: «La ciudad, está bien, necesitamos este contacto. [Pero] yo no cambiaría, no cambiaría [...] mi casita, mi área rural por una ciudad. No cambaría, aunque yo piense que sea importante de tener este contacto [...]. Tenemos que salir, pero para vivir realmente, está bien aquí», ${ }^{32}$ «La ciudad, está bien, porque hay recursos. Ahí, hay un hospital, hay tecnologías que no hay aquí, tenemos que ir a la ciudad. La ciudad es muy importante. Pero prefiero aquí, porque es sosegado». 33 
A pesar de esos discursos positivos con respecto al futuro de la ruralidad de la comunidad quilombola, las emigraciones urbanas existían y siguen existiendo. Acevedo y Castro (2004: 51) identifican tres principales motivos de emigración en Abacatal: matrimonio, trabajo y educación. Entre las 24 familias entrevistadas (esencialmente en un intervalo de 25 y 55 años) se encuentra un contingente de 42 individuos (hermanos y hermanas o hijos e hijas) que migraron de forma definitiva (lo que equivale a una media de 1.75 individuos por familia). Entre ellos, 28 -o sea el $66.7 \%$ de la muestra- migraron a zonas urbanas, mayoritariamente dentro de la región bragantina del estado del Pará, ${ }^{34}$ Observamos, entonces, una emigración notable, sin que amenace, por el momento, el crecimiento demográfico da la comunidad. En efecto, la población total de Abacatal creció de 65 familias (unos 280 individuos) en $2008^{35}$ a un total de 76 familias (aproximadamente 330 individuos) en $2010 .{ }^{36}$ Además, entre los habitantes actuales de Abacatal observamos, a través de sus discursos, pocos deseos de emigración, lo que puede permitir reformular, por lo menos parcialmente, la cuestión de las migraciones desde las áreas rurales hacia las urbanas. Así, las situaciones de co-residencia -tanto como los casos de trabajadores asalariados- entre trabajador rural clásico y migrante son una buena ilustración de esta realidad. Finalmente, tales fenómenos incitan a repensar la ruralidad, capaz de adaptarse y renovarse, en su relación con la modernidad en nuevos contextos y realidades. A menudo los emigrantes mantienen un sentimiento de pertenencia a la comunidad quilombola y a veces manifiestan la intención de regresar a la tierra de nacimiento (real o ficticia). Es por esto que ciertos habitantes de Abacatal que migraron a la ciudad conservan profundos vínculos con la comunidad: familiares, obviamente, pero también vínculos directamente arraigados en la tierra y la ruralidad, gracias a prácticas y costumbres rurales. Esos mecanismos muestran más que una asimilación, evidencian tanto las formas de adaptación del espacio rural a los nuevos desafíos urbanos como un deseo real de preservar y resaltar los valores de la ruralidad. Ese tipo de observaciones permite a Padoch et al. (2008: 4) decir: «Categorizar a las personas, las unidades domésticas, e incluso las comunidades en Amazonia es difícil, porque los espacios y las personas rurales y urbanos se vinculan inextricablemente de numerosas formas (Wagley, 1953; Nugent, 1993; WinklerPrins, 2002; 
WinklerPris y Souza, 2005; Siqueira, 2006). Buena parte de las nuevas unidades domésticas urbanas son «multisituadas», «multilocales» o dispersadas, manteniendo casas, y comúnmente, actividades económicas en las áreas rurales como en las áreas urbanas».

En este contexto, mientras los quilombolas abren sus territorios y sus prácticas a las influencias de la ciudad, también esbozan un movimiento de repliegue territorial e identitario que se caracteriza, entre otros, por una valorización de la ruralidad. En aras de controlar las fronteras de la comunidad rural se organiza todo un sistema. En Abacatal, frente a la amenaza de la presión urbana, se instaló un portal en la entrada de la comunidad. Este encarna la ambivalencia de la comunidad quilombola con respecto a su relación con la ciudad: por una parte, un portal poroso que deja ciertos flujos de personas y bienes (familia y amigos, bienes mercantiles y de consumo) transitar y, por otra, un portal que cierra e impide las influencias urbanas supuestamente amenazadoras. Aparece finalmente como una clase de filtro selectivo en relación con el exterior (especialmente la ciudad) y sus peligros potenciales. Expresa el deseo de quedarse en el grupo de pertenencia, representando tanto el repliegue frente a cierto «afuera» como un acercamiento hacia un «adentro». De esta forma, este elemento es percibido como el nuevo objeto de lucha frente a un «Otro» constantemente renovado. De la misma manera, la instalación en el territorio quilombola y la pertenencia a la comunidad son regidas por estrictas reglas; por ejemplo, respecto al parentesco, cuya influencia es muy fuerte. Finalmente, surgen fronteras para garantizar la protección y la preservación de los espacios vitales de la comunidad; espacios rurales en este caso, espacios de vida y de producción. En efecto, se trata también de una frontera porosa que admite los intercambios y las relaciones. No se presenta como una línea de ruptura, sino como un espacio flexible que delimita. No se trata tanto de una frontera que cierra, sino de una frontera que define y distingue los espacios y las sociedades. 
DIFERENCIACIÓN DE LOS TERRITORIOS, DIFERENCIACIÓN DE LAS SOCIEDADES: UNA RURALIDAD INTEGRADORA Y SITUACIONAL.

Como mecanismo territorial e identitario, la diferenciación es un elemento clave para la comprensión de los procesos sociales quilombolas. En este contexto, la identidad rural aparece como un medio para afirmarse como quilombolas y, al mismo tiempo, para afirmar la necesidad de un territorio independiente, territorio-identidad y territorio-recurso. Así, la ruralidad que caracteriza y define a las poblaciones quilombolas es una ruralidad diferenciada, que les permite no desaparecer en la masa confusa, estigmatizada y popular de los pobres, negros o cualquier otro caboclo, caïpira o pequeño trabajador rural. Despreciado e invisibilizado, el pequeño trabajador rural caboclo o caïpira encarna «simultáneamente la víctima y el que perpetúa el subdesarrollo brasileño» (Brondizio en Adams et al., 2006:195). La ruralidad propiamente quilombola aparece como una valorización de lo que son y de lo que hacen, ofreciendo una especificidad que los distingue de sus vecinos, incluso aunque estos sean aparentemente muy parecidos. Esta reivindicación les da, finalmente, la posibilidad de singularizarse en la escena pública o simplemente de participar en ella.

Es por esto que la diferenciación resulta bastante estratégica. Ser quilombola confiere un estatuto particular del que estas poblaciones, a menudo desconsideradas, carecían. Aquella identidad restaura su propia imagen y aparece como una oportunidad que hay que preservar. Sin embargo, influencias exteriores demasiado numerosas y demasiado frecuentes serían sinónimo de urbanización, dilución del territorio, del grupo social y, sobre todo, de la identidad quilombola. Pues mientras «los caboclos no tienen ni identidad ni defensores» (Adams et al., 2006: 82), los quilombolas son gratificados con una identidad rural y cultural e integrados a una red político-asociativa densa y activa. En efecto, con el tiempo, los quilombolas han aprendido a unirse y organizarse tanto localmente (por ejemplo, la ARQMO, Asociación de los Remanentes Quilombolas del Municipio de Oriximiná; PA, federación municipal de comunidades quilombolas, o la Malungu, organización estatal designada como Coordinación de las Asociaciones de las Comunidades 
Remanentes de Quilombos del Pará) como de manera federal (con la CONAQ, Coordinación Nacional de Articulación de Comunidades Negras Rurales Quilombolas). Han conseguido también alianzas y apoyos de numerosas instituciones cívicas (asociaciones de defensa de los afro-descendientes como el CEDENPA, Centro de Estudios y Defensa del Negro del Pará; organismo de protección de la diversidad cultural y ecológica como la CPI-SP, Comisión Pro-Indio de São Paulo, o el ISA, Instituto Socioambiental), religiosas (la más famosa es la CPT, Comisión Pastoral de la Tierra, también relevada por las parroquias locales) o políticas (a través, por ejemplo, de los órganos de la Organización de las Naciones Unidas, como la OIT, Organización Internacional del Trabajo o el PNUD, Programa de las Naciones Unidas para el Desarrollo y su proyecto «Quilombolas de las Américas», iniciado en 2010). Esta nueva identidad, altamente valorizante, mueve también numerosas ventajas socioeconómicas (gracias a la afluencia de proyectos de todo tipo con destino específico hacia las comunidades quilombolas) y derechos diferenciados. Se trata, para estas poblaciones, de aprovechar oportunamente las especificidades identitarias, económicas y territoriales.

La ruralidad, combinada con rasgos étnicos y tradicionales, se hace para los quilombolas un signo distintivo, una manera de singularizarse; por esto se trata de una ruralidad diferenciada pero también integradora. En efecto, Brasil es un país multicultural, en donde la diversidad se ha elevado a la categoría de principio. En los años ochenta, gracias a un cambio de paradigma, se rechazó la concepción nacionalista y homogénea del EstadoNación que reducía la Historia Nacional a las aventuras e infortunios de los mayoritarios, sin tener en cuenta la contribución de los «Otros» a la edificación y a la transformación de la sociedad nacional (Ribeiro, 1995). Como lo explica Juteau, «se trata de reconocer a los inmigrantes y a sus descendientes, a las minorías étnicas o nacionales, la posibilidad de conservar o de transformar según su voluntad sus prácticas y valores, su memoria histórica y su identidad» (1999: 196). Pues gracias al pluralismo normativo generalizado, la nación volvió a construirse integrando sus márgenes invisibles. La Constitución Federal de 1998 impulsa una nueva tendencia, otorgando a las poblaciones indígenas y a los descendientes 
de esclavos cimarrones un estatuto específico, legítimo y reconocido, acompañado con derechos diferenciados. La diversidad y la diferenciación se presentan así como el principio inherente a una brasilianidad en reconstrucción, reforzado por un fuerte deseo de reparar y compensar las ofensas contra las poblaciones minoritarias y tradicionalmente dominadas.

Declararse «Otro» se vuelve un medio para entrar en un sistema más global (brasileño), en el que la diferencia parece ser la clave, apoyada por la afirmación y la valorización de una ruralidad multiforme. Todo esto permite a los grupos quilombolas conseguir diversas ventajas (económicas, sociales y políticas) y atraer los proyectos, al abandonar los oropeles de negros, pobres y rurales estigmatizados. Esta nueva identidad constituye una estrategia de reproducción y de supervivencia para esos caboclos «modernos en su renovación constante del pasado en el presente» (Adams et al., 2006:81). El pequeño productor rural, en tanto agente activo, toma decisiones y es capaz de cambiar su situación de forma dinámica. El caboclo, frecuentemente tachado de arcaísmo, vive enteramente en un presente y una modernidad que sabe aprovechar. Los quilombolas aprenden así a navegar entre esta fuerte conciencia del presente y de la modernidad y un nuevo arraigo en un pasado mitificado; ambivalencia que se encarna finalmente en los contornos de una ruralidad renovada.

Para terminar, la ruralidad quilombola parece entenderse en la diferencia, más precisamente en la diferenciación, lo que da a estas poblaciones una característica que ellos esgrimen como argumento en su búsqueda de una identidad y de un territorio específicos. Pero la ruralidad es estratégica como vector de diferenciación tanto como de integración, al permitir a los quilombolas definirse e insertarse en un sistema de categorización nacional en el que están presentes al lado de otras figuras taxonómicas tales como los indios o las poblaciones tradicionales. La ruralidad expresada por los quilombolas muestra flexibilidad y permeabilidad. Se adapta a las circunstancias y riesgos de la modernidad, se centra en los valores tradicionales y ancestrales para alimentarse de las prácticas modernas de la ciudad sin por esto asimilarse. De ahí que esta pueda considerarse decididamente como situacional, 
unas veces etnicizada para probar su carácter inmemorial, otras para permitir a los quilombolas convertirse en actores del desarrollo sostenible, otras veces urbana, para aprovechar las ventajas y oportunidades de las ciudades, gigantescos mercados de clientela, trabajo, productos y servicios; pero finalmente, ante todo, moderna en su ambivalencia.

\section{CONCLUSIONES}

Los discursos de los unos y de los otros evidencian una ruralidad quilombola claramente multiforme, que se perfila según las características de la identidad. Escindida entre la modernidad y la tradición, la ruralidad quilombola revela su ambivalencia. Es a la vez una estrategia y una valorización identitaria, alimentada por las reivindicaciones de las poblaciones y por las categorías políticas subyacentes. En este contexto en el que la ruralidad aparece como un indicio de la renovación rural brasileña, esta se convierte en una oportunidad. Lo rural se reactualiza como campo socioterritorial complejo y diversificado que no se contenta con objetivos económicos, sino que se inclina hacia preocupaciones culturales y ambientales.

Ello implica que este nuevo tipo de ruralidad no puede entenderse fuera de un contexto más amplio. Se trata sencillamente de una de las numerosas declinaciones de una neo-ruralidad en la cual la agricultura familiar encuentra un lugar destacado, de manera que las comunidades rurales se integren y se valoricen. Se consolidan «micro-sociedades estabilizadas, (...) [dinámicas y] portadoras de un proyecto social y político afirmado que da pruebas del acceso a una verdadera ciudadanía» (Jollivet en Zanoni et al., 2001: 8). Esta se declina según varias formas : comunidades remanentes de quilombos, Tierras Indígenas (TI), Reservas Extractivistas (Resex), Reservas de Desarrollo Sostenible (RDS), Proyectos de Instalación Agro-Extractivista (PAE), entre otros tipos de figuras. Estas recientes estructuras productivas salen a luz como nuevos espacios y nuevas posibilidades de reproducción e integración social. En efecto, además de la valorización del trabajo rural y de ciertas formas de cultura que implican, ofrecen a esas franjas marginadas la seguridad fundiaria en un contexto de presiones incrementadas sobre las tierras. Así, ser rural se 
vuelve, a su turno, vector de integración en la sociedad global nacional. Se evidencian entonces las «soluciones» más que los problemas que el mundo rural puede traer. Este último, redinamizado, parece tener sus propios valores. La agricultura de subsistencia, combinada con una agricultura comercial es valorizada como el modo y la calidad de vida rurales, las relaciones interpersonales, los contactos directos e intensos con la naturaleza y una forma de «tradición inventada» ${ }^{37}$ (Hobsbawm y Ranger, 2006). Es así como el desarrollo rural se hace sostenible. La ruralidad ya no se limita a la dimensión productiva de la agricultura e incluye los mecanismos de «revitalización de las sociabilidades permitidas por la extensión a escala local de medios diferenciados de integración social y de participación en el patrimonio cultural común y por el acceso a otras condiciones de ejercicio de la ciudadanía» (Zanoni et al., 2001).

Así, entre el campesino y el agricultor (Deléage, 2005) se encuentra una tercera figura rural que podríamos llamar el «agricultor familiar alternativo-sostenible» (Brandenburg en Zanoni et al., 2001:175). Sus características podrían definirse de la forma siguiente:

Cuadro 2: Propuesta de otra tipología rural, a partir de Deléage (2005: 18).

\begin{tabular}{|c|c|c|c|}
\hline \multirow{7}{*}{ Valores } & Campesino & $\begin{array}{c}\text { «Agricultor familiar } \\
\text { alternativo-sostenible» }\end{array}$ & Agricultor \\
\cline { 2 - 4 } & Estabilidad & Adaptación & Cambio \\
\cline { 2 - 4 } & Arraigo & Movilidad & Desarraigo \\
\cline { 2 - 4 } & Polivalencia & Pluriactividad & Especialización \\
\cline { 2 - 4 } & Papel de la tradición & «Tradición inventada» & $\begin{array}{c}\text { Papel de la tecnología y } \\
\text { del mercado }\end{array}$ \\
\cline { 2 - 4 } & $\begin{array}{c}\text { Economía de } \\
\text { autosubsistencia }\end{array}$ & $\begin{array}{c}\text { Lógica de subsistencia y } \\
\text { de mercado }\end{array}$ & $\begin{array}{c}\text { Economía mercantil e } \\
\text { industrial }\end{array}$ \\
\hline Racionalidad & Social y moral & $\begin{array}{c}\text { Sociocultural, ecológica } \\
\text { y económica }\end{array}$ & Técnica y económica \\
\hline
\end{tabular}

Fuente: A partir de Deléage 2005: 18. 
Se distinguen tres mundos rurales que forman una especie de gradiente (Deléage, 2005: 1819). Mientras que la clase de los campesinos agrupa a los trabajadores rurales excluidos de la economía de mercado, condenados a desaparecer, los agricultores se integran en la economía agroalimentaria; ellos saben usar las nuevas tecnologías y suelen desempeñar un papel en la vida política y social tanto local como internacionalmente. Entre esas dos figuras está el «agricultor familiar alternativo-sostenible», que tiene un bajo nivel de capitalización pero aprende a diversificarse y desarrolla actividades de nicho. Pero, como Deléage (2005: 18-19) lo subraya, puede ser una posición frágil. En efecto, a pesar de la actualidad del modelo y de sus promesas, parece necesario interrogarse sobre su viabilidad más allá de las primeras generaciones beneficiarias, ¿̇será que los más jóvenes prefieran quedarse en el campo o tentar otra vida en la ciudad?

\section{BIBLIOGRAFÍA}

Acevedo Marin, Rosa y Edna Ramos Castro, 2004, No caminho das Pedras de Abacatal, NAEA / UFPA, Belém.

Adams, Cristina, Rui Murrieta y Walter Neves (orgs.), 2006, Sociedades caboclas amazônicas. Modernidade e invisibilidade, Annablume, São Paulo.

Andrade, Lúcia M. (dir.), 2007, Terra de Quilombo. Herança e Direito, CPISP, São Paulo.

Barth, Fredrik, 1995, «Les groupes ethniques et leurs frontières», en Théories de l'ethnicité, editado por Philippe Poutignat y Jocelyne Streiff-Fenart, PUF, París, pp. 203-249.

Bonnemaison, Joël, 1981, «Voyage autour du territoire», L’Espace Géographique, n. 4, Paris, pp. 249-262.

Deléage, Estelle, 2005, La fin des paysans: mythe ou réalité?, Colloque Faire Campagne, 17-18 de marzo, Rennes. 
Di Méo, Guy y Pascal Buléon, 2005, L’espace social. Lecture géographique des sociétés, Armand Colin, Paris.

Godoi, Emilia Pietrafesa de, Marilda Aparecida de Menezes y Rosa Acevedo Marin (orgs.), 2009, Diversidade do campesinato : expressões e categorias, vol. II Estratégias de reprodução social, Editora UNESP, São Paulo.

Graf, Fabio et al., 2007, Banana orgânica no Quilombo de Ivaporunduva-Uma experiência de desenvolvimento sustentável, Instituto Socioambiental, São Paulo.

Haesbaert, Rogério, 2007, O mito da desterritorialização, do « Fim dos Territorios » à Multiterritorialidade, Bertrand Brasil, Rio de Janeiro.

Hobsbawm, Eric y Terence Ranger (dir.), 2006, L’invention de la Tradition, Ed. Amsterdam, Paris.

ITERPA/DEAF/CEP/GCQ, 2010, Plano de Utilização dos remanescentes de quilombo de Abacatal, Secretaria de Estado de Agricultura/ITERPA, Belém.

Jean, Bruno, 1997, Territoires d’avenir. Pour une sociolgie de la ruralité, Presses de l’Université du Québec, Sainte-Foy.

Juteau, Danielle, 1999, L'ethnicité et ses frontières, Les Presses de l’Université de Montréal, Montréal.

Kayser, Bernard, 1990, La renaissance rurale. Sociologie des campagnes du monde occidental, Armand Colin, Paris. 
Lamarche, Hugues (coord.), 1991, L’agriculture familiale. I ; Une réalité polymorphe. Comparaison internationale, L’Harmattan, Paris.

Larrea Killinger, Cristina y José Luis Ruíz-Peinado Alonso, 2004, «Memoria y território quilombola en Brasil», en Quaderns de l'Institut Català d'Antropologia, n. 20, pp. 191-215.

Medeiros Paoliello, Renata, 2006, «Estratégias espaciais, reconversões identitárias e novas ruralidades em terras remanescentes de quilombos», VII Congreso Latinoamericano de Sociología rural, Quito.

Mendras, Henri, 1967, La fin des paysans, innovations et changements dans l'agriculture française, SEDEIS, Paris.

Mendras, Henri, 1995, Sociétés paysannes : éléments pour une théorie de la paysannerie, Folio, Paris.

Pacheco dos Santos, Kátia y Nilto Tatto (eds.), Agenda socioambiental de comunidades quilombolas do Vale do Ribeira, Instituto Socioambiental, São Paulo.

Padoch, Christine, Eduardo S. Brondizio, Sandra Costa et al., 2008, «Urban Forest and Rural Cities: Multi-sited Households, Consumption Patterns and Forest Resources in Amazonia», Ecology and Society, tomo XIII, n. 2.

Raimbert, Céline, 2009, «Communauté et territoires. Le cas du village quilombola d’Abacatal dans le Grand Belém, Pará», Tesis de maestría, Université de Paris IIISorbonne Nouvelle/IHEAL-CREDAL, Paris.

Ribeiro, Darcy, 1995, O povo brasileiro. A formação e o sentido do Brasil, Companhia das Letras, São Paulo. 
Santilli, Juliana, 2005, Socioambientalismo e novos direitos. Proteção jurídica à diversidade biológica e cultural, Peirópolis, São Paulo.

Thomsin, Laurence, 2001, «Un concept pour le décrire : l'espace rural urbanisé», Ruralia, n. 9.

Véran, Jean-François, 2003, L'esclavage en héritage (Brésil). Le droit à la terre des descendants de marrons, Khartala, Paris.

Zanoni, Magda y Hugues Lamarche (coords.), 2001, Agriculture et ruralité au Brésil. Un autre modèle de développement, Khartala, Paris.

\section{NOTAS}

${ }^{1}$ CIA Factbook, 2010. URL : https:/www.cia.gov/library/publications/the-world-factbook/geos/br.html, consultado en 03/01/2012.

${ }^{2}$ OMC, Organización Mundial del Comercio, 2010.

${ }^{3}$ Mientras que en 1950 el 63.84\% de la población brasileña vivía en el medio rural, treinta años después la tendencia se invirtió, los rurales representan solo el 32.30\% de la población total en 1980, para caer hasta el 15.64\% en 2010. IBGE, Instituto Brasileño de Geografía y Estadística.

${ }^{4}$ Los riesgos que esas evoluciones implican ya fueron muy estudiados: urbanización del campo (Thomsin, 2001), éxodo rural, fin del campesinado (Mendras, 1967), etcétera.

${ }^{5}$ Se trata de un movimiento social de inspiración marxista y cristiana progresistas (teología de la liberación), cuyo objetivo principal es la realización de la reforma agraria en Brasil.

${ }^{6}$ Según Santilli (2005: 34), «el socioambientalismo se ha construido basándose en la idea que las políticas públicas ambientales deben incluir e implicar a las comunidades locales, poseedoras de conocimientos y de prácticas de gestión ambiental».

${ }^{7}$ Bajo la presidencia de Luís Inácio Lula da Silva.

${ }^{8}$ Datos extraídos de ITERPA/DEAF/CEP/GCQ, 2010, Plano de Utilização dos remanescentes de quilombo de Abacatal, Secretaria de Estado de Agricultura/ITERPA, Belém.

${ }^{9}$ Caïpira es el nombre genérico dado en la región de São Paulo y Minas Gerais a los campesinos, sean blancos o negros.

${ }^{10}$ Originariamente, se designan así a los mestizos descendientes de europeos blancos con indígenas. Hoy en día, los caboclos representan la mayor parte de los campesinos de la cuenca amazónica.

${ }^{11}$ Los ribereños (ribeirinhos, en portugués) son las poblaciones rurales que viven en las proximidades de los ríos y cuya actividad principal se comparte entre la pesca artesanal y el agroextractivismo.

${ }^{12}$ Para más informaciones sobre la construcción histórica de las comunidades quilombolas, consultar Larrea Killinger y Ruiz-Peinado Alonso, 2004.

${ }^{13}$ Datos de campo (2008). Título de la pregunta del cuestionario socioeconómico: «¿Cuál es la mayor fuente de ingresos de la unidad doméstica?» / respuesta abierta. 
${ }^{14}$ La reflexión que desarrollamos aquí se basa en informaciones recogidas en el campo a partir de entrevistas abiertas y otras conversaciones informales.

${ }^{15}$ Para más informaciones sobre la historia de Abacatal, $c f$. Acevedo y Castro, 2004.

${ }^{16}$ Según Acevedo y Castro (2004), la superficie actual de Abacatal (583, 2838 ha) correspondería al 15\% del territorio inicial del conde que nunca fue delimitado de forma clara. Pero con el tiempo el territorio originario de las Tres Marías sufrió apropiaciones de particulares (como Justino Canuto Santos y Félix Emanuel Teixeira de Oliveira), así como de empresas o instituciones (la empresa neumática Pirelli, el órgano gubernamental Embrapa -Empresa Brasileña de Investigación Agropecuária) (Acevedo y Castro, 2004).

17 «Grilagem» es una palabra portuguesa que designa el acto de apropiarse ilegalmente una tierra, emitiendo falsos títulos. La disputa por la tierra y sus consecuencias son detalladas en Acevedo y Castro, 2004.

${ }^{18}$ Según Acevedo y Castro (2004: 18), la primera acción de «grilagem» se inicia con la publicación del Decreto $n^{\circ} 2.285$ del 12/06/1957. Otorga al señor Justino Canuto Santos «un lote de tierras en el municipio de Ananindeua, cual área pertenece a terceros». Cuando él decidió vender esas tierras en los años 1987-1988, los conflictos empezaron, los nuevos propietarios quisieron expulsar a los ocupantes ilegales. Después los dueños, con la policía, se enfrentaron con los abacataenses, apoyados por asociaciones culturales y religiosas de la región en su reivindicación por el reconocimiento de su identidad quilombola y los derechos territoriales que la acompañan.

${ }^{19}$ El señor Benedito Rosa da Conceição, 74 años, trabajador rural retirado, es el descendiente directo de una de las «Tres Marías » y siempre se ha quedado en la comunidad de Abacatal, donde vive con su esposa, dos hijas y dos nietas. Entrevista realizada en diciembre de 2008.

${ }^{20}$ Son especies de yuca.

${ }^{21}$ Palabras de María Santana da Costa Barbosa, 40 años, trabajadora rural. Descendiente de la familia de una de las «Tres Marías», ella forma parte con otros miembros de su familia (hermanos y marido) del liderazgo de la comunidad quilombola de Abacatal. Entrevista realizada en 2008.

${ }^{22}$ El INCRA, Instituto Nacional de Colonización y Reforma Agraria, es el órgano federal encargado para la titularización de las tierras quilombolas.

${ }^{23}$ Él afirma que el artículo 68 de las Disposiciones Transitorias, que reconocen a los quilombolas sus derechos territoriales, se presenta como «el encuentro entre la oferta política del quilombo que define un «derecho cultural» y las reivindicaciones de esas «comunidades», motivadas por algunos imperativos de supervivencia y la urgencia de los conflictos fundiarios» (Véran, 2001:8).

${ }^{24}$ Analizando las definiciones oficiales de las poblaciones indígenas y quilombolas, Santilli (2005: 135) evidencia características dadas como «gestión y uso compartidos de los recursos naturales existentes en sus territorios (...) y conocimientos, innovaciones y prácticas colectivas, relevantes para la conservación y el uso sostenible de la biodiversidad».

${ }^{25}$ El Vale do Ribeira corresponde a la cuenca hidrográfica del río Ribeira de Iguape y se extiende entre los estados de São Paulo y Paraná. Esta región aloja el 61\% de la selva atlántica brasileña, famosa por su extraordinaria biodiversidad. Es también el lugar donde se encuentran numerosas unidades de conservación y la mayoría de las comunidades quilombolas del estado de São Paulo. Entre ellas, nos referiremos aquí sobre todo a la comunidad de Ivaporunduva, la más antigua y más famosa de las comunidades quilombolas del Vale do Ribeira. Titulada en 2003, cuenta con 320 individuos distribuidos sobre 2,754.36 ha. Para más informaciones, consultar Pacheco dos Santos y Tatto, 2008.

${ }^{26}$ El Instituto Socioambiental (ISA) es una organización no gubernamental fundada en 1994, cuyo objetivo principal es «defender bienes y derechos sociales, colectivos y difusos relativos al medio ambiente, al patrimonio cultural y a los derechos humanos y de los pueblos y valorizar la diversidad socioambiental». Así, muchas acciones se hacen a favor de los pueblos indígenas y quilombolas. Señalamos también que el ISA tiene un programa especial dedicado al Vale do Ribeira para «ayudar a la construcción de políticas públicas sobre las relaciones entre los recursos hídricos y naturales y las comunidades tradicionales». Para más informaciones, consultar: http://www.socioambiental.org/

${ }^{27}$ Para más informaciones sobre ese proyecto, consultar Graf, 2007.

${ }^{28}$ Término francés que designa «un espacio geográfico delimitado definido a partir de una comunidad humana que construye durante su historia un conjunto de rasgos culturales distintivos, de saberes y de 
prácticas basadas en un sistema de interacciones entre el medio natural y los factores humanos. Las habilidades puestas en juego revelan una originalidad, confieren una tipicidad y permiten un reconocimiento para los productos o servicios originarios de este espacio, así como para los hombres que viven ahí. Los «terroirs» son espacios vivos e innovadores que no pueden solo equipararse con la tradición». (Definición validada por la UNESCO, 2005.)

${ }^{29}$ Estos cálculos no tienen en cuenta a los trabajadores asalariados de forma temporal y puntual. Datos de campo (2008). Los cálculos de 1998 se basan en los datos del Programa Raíces (actual SEPPIR, Secretaría Especial de las Políticas de Promoción de la Igualdad Racial), 14 de septiembre de 1998.

${ }^{30}$ La importancia de ese fenómeno cabe en su magnitud actual : «Aunque las parejas multi-localizadas no son nuevas en Amazonia, recientes cambios en las comunicaciones y los transportes, los mercados y las oportunidades de trabajo han reforzado la importancia de ese modelo residencial y económico» (Padoch et al., 2008:4)

${ }^{31}$ En su definición clásica, la urbanización del campo designa «un proceso de integración (especialmente cultural) bajo la influencia de las ciudades», parecido a una asimilación pura y simple.

${ }^{32}$ Palabras de Maria Luciana Silva e Silva, 29 años, profesora en la escuela de Abacatal. Entrevista realizada en 2008.

${ }^{33}$ Palabras de Joaquim Cordeiro dos Santos, 49 años, trabajador rural. Entrevista realizada en 2008.

${ }^{34}$ La región bragantina corresponde a la parte nordeste del estado del Pará, área de influencia de Belém.

${ }^{35}$ Datos de campo (2008).

${ }^{36}$ Datos extraídos de ITERPA/DEAF/CEP/GCQ, 2010, Plano de Utilização dos remanescentes de quilombo de Abacatal, Secretaria de Estado de Agricultura/ITERPA, Belém.

${ }^{37}$ Como Hobsbawm y Ranger lo muestran, la tradición se relaciona con la modernidad, la primera parece ser una invención de la segunda. A pesar de su referencia al pasado, la tradición permanece muy presente: «Intentando establecer una continuidad con un pasado histórico apropiado, (...) la particularidad de las «tradiciones inventadas» se debe al hecho que su continuidad con ese pasado es ampliamente ficticio. En pocas palabras, son respuestas a situaciones nuevas (...). Es el contraste entre el cambio permanente, la innovación del mundo moderno y la tentativa de estructurar por lo menos ciertas partes de la vida social como inflexibles e invariantes» (2006: 12).

Fecha de recepción: 10 de diciembre de 2010.

Fecha de aceptación: 9 de enero de 2012. 